\title{
Estuarine and Tidal Freshwater Habitat Cover Types Along the Lower Columbia River Estuary Determined from \\ Landsat 7 Enhanced Thematic Mapper (ETM+) Imagery
}

Technical Report

2003

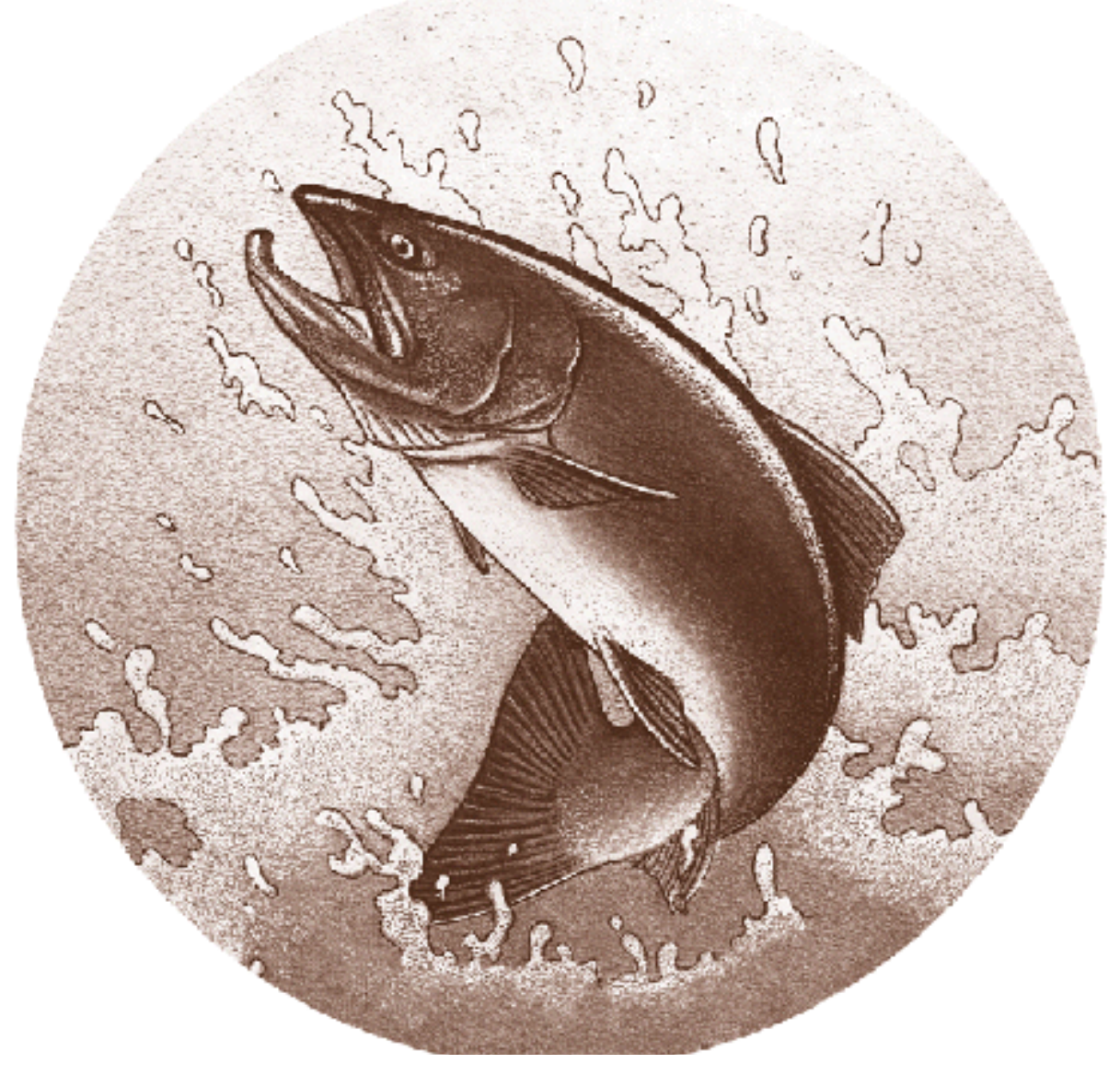

DOE/BP-00008768-3

October 2003 
This Document should be cited as follows:

Garono, Ralph, Rob Robinson, "Estuarine and Tidal Freshwater Habitat Cover Types

Along the Lower Columbia River Estuary Determined from Landsat 7 Enhanced Thematic

Mapper (ETM+) Imagery", Project No. 2002-01200, 29 electronic pages, (BPA Report

DOE/BP-00008768-3)

Bonneville Power Administration

P.O. Box 3621

Portland, Oregon 97208

This report was funded by the Bonneville Power Administration (BPA), U.S. Department of Energy, as part of BPA's program to protect, mitigate, and enhance fish and wildlife affected by the development and operation of hydroelectric facilities on the Columbia River and its tributaries. The views in this report are the author's and do not necessarily represent the views of BPA. 


\section{Estuarine and Tidal Freshwater Habitat Cover Types Along the Lower Columbia River Estuary Determined from Landsat 7 ETM+ Imagery}

October 2003

Submitted to

Bonneville Power Administration

US Army Corps of Engineers

Lower Columbia River Estuary Partnership

Bonneville

Iinin

Ralph J. Garono \& Rob Robinson

Wetland \& Watershed Assessment Group, Earth Design Consultants, Inc.

in cooperation with

\section{Charles Simenstad \\ Wetland Ecosystem Team}

School of Aquatic and Fishery Sciences, University of Washington

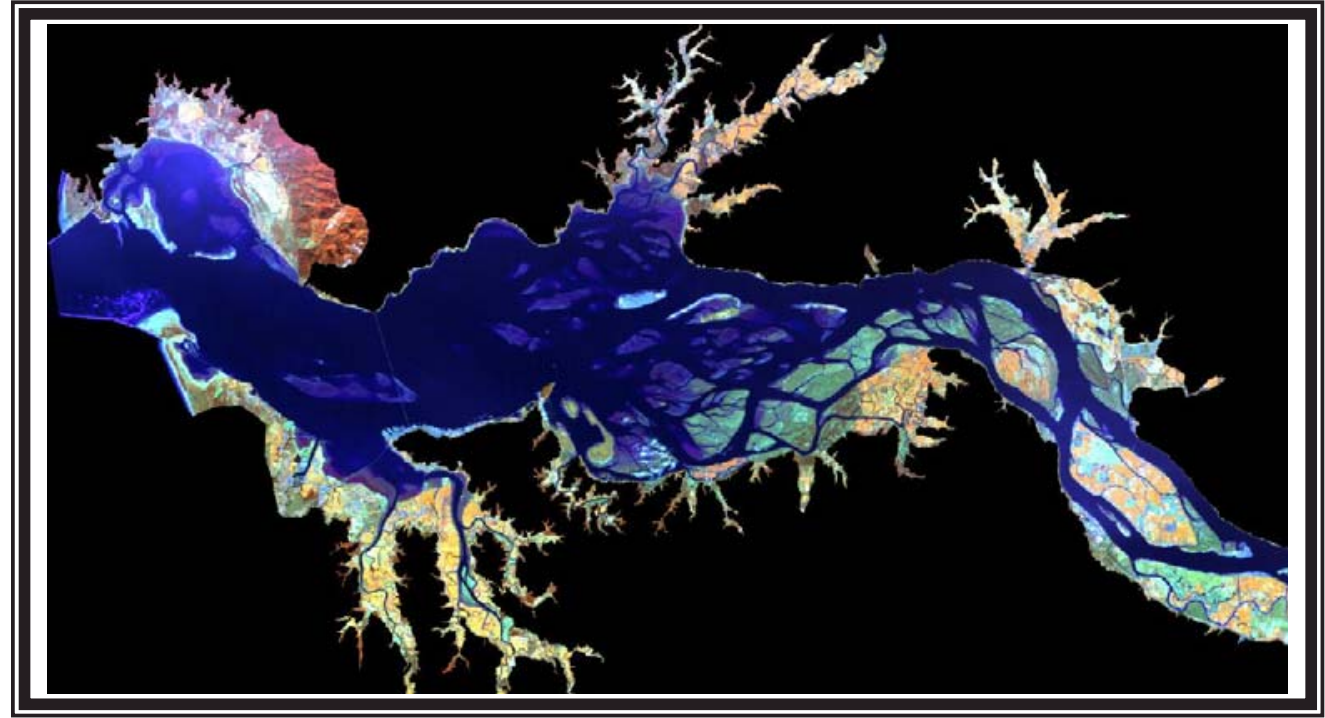

Wetland \& Watershed Assessment Group

Earth Design Consultants, Inc.

230 SW Third St., Suite 212

Corvallis, OR 97333

541.757 .7896

http://www.earthdesign.com 


\section{Table of Contents}

TABLE OF CONTENTS ..................................................................................................... 1

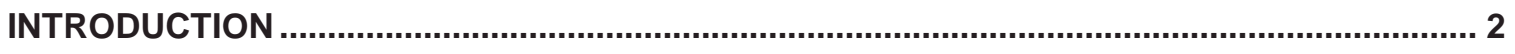

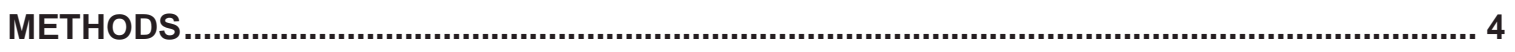

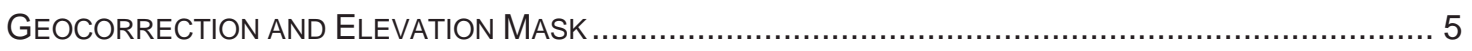

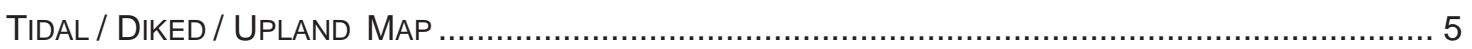

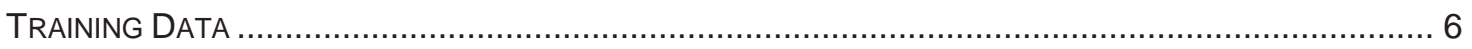

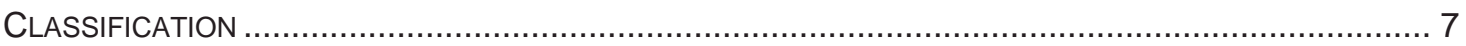

RESULTS

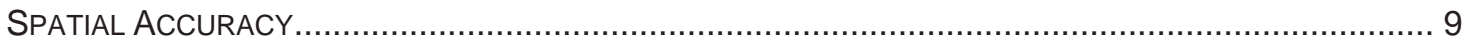

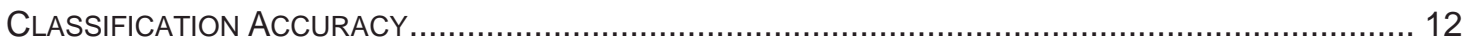

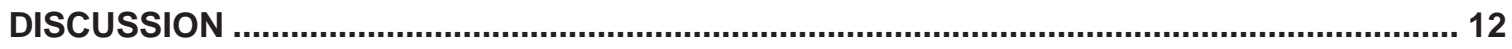

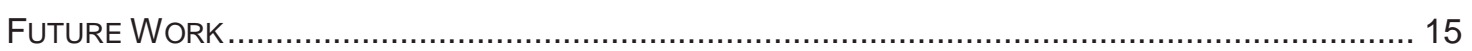

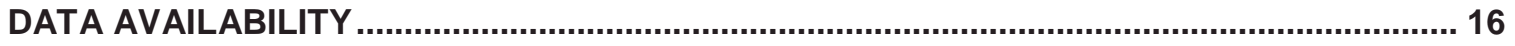

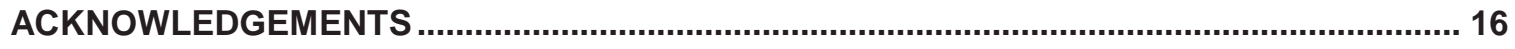

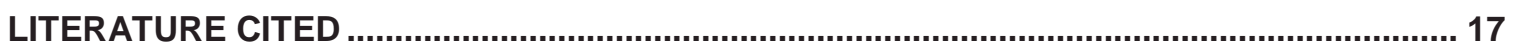

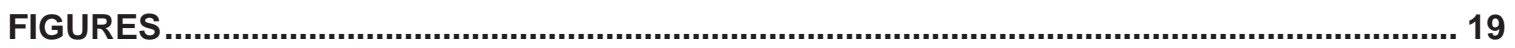




\section{Introduction}

Developing an understanding of the distribution and changes in estuarine and tidal floodplain ecosystems is critical to the management of biological resources in the lower Columbia River. Columbia River plants, fish, and wildlife require specific physicochemical and ecological conditions to sustain their populations. As habitats are degraded or lost, this capability is altered, often irretrievably; those species that cannot adapt are lost from the ecosystem. The Lower Columbia River Estuary Partnership (Estuary Partnership) completed a comprehensive ecosystem protection and enhancement plan for the lower Columbia River and estuary in 1999 (Jerrick, 1999). The plan identified habitat loss and modification as a critical threat to the integrity of the lower Columbia River ecosystem and called for a habitat inventory as a key first step in its longterm restoration efforts.

In 2000, the Estuary Partnership initiated a multiphase project to produce a spatial data set describing the current location and distribution of estuarine and tidal freshwater habitat cover types along the lower Columbia River from the river mouth to the Bonneville Dam using a consistent methodology and data sources (Fig. 1). The first phase of the project was the development of a broadbrush description of the estuarine and tidal freshwater habitat cover classes for the entire study area ( 146 river miles) using Landsat 7 ETM+ satellite imagery. Phase II of the project entailed analysis of the classified satellite imagery from Phase I. Analysis of change in landcover and a summary of the spatial relationships between cover types are part of Phase II. Phase III of the project included the classification of the high resolution hyperspectral imagery collected in 2000 and 2001 for key focal areas within the larger study area. Finally, Phase IV consists of this final report that presents results from refining the Landsat ETM+ classification and provides recommendations for future actions.

Previous studies (Thomas, 1980; Thomas, 1983; Graves et al., 1995; NOAA, 1997; Allen, 1999) produced similar landcover data sets; however, most 
of these studies used multiple and varied data sources and differed from one another in methodologies. Currently, no single data set has been produced using a consistent methodology and uniform scale data, which describes current estuarine and tidal freshwater floodplain cover types from the Columbia's mouth to the Bonneville Dam (Fig. 1).

Results from this study will be used by the Estuary Partnership and its cooperators to: (1) develop indicators of "habitat health" for target species and populations, and biological integrity at the community and ecosystem scales; (2) develop definitions of "important salmonid habitat"; (3) identify and evaluate potential wetland conservation and restoration sites; (4) track non-indigenous and invasive species; and (5) develop an understanding of how estuarine and floodplain habitats have changed over the past 200 years. This study focused on estuarine and tidal freshwater floodplain habitat cover types, which are important to native species, particularly juvenile salmonids. Results from this study are meant to provide support for the multiple efforts currently underway to recover 12 species of Columbia River salmonids identified as endangered or threatened under the Endangered Species Act.

Spatial scale was an important consideration in this study. Our goal was to create a geographic information system (GIS) coverage depicting habitat cover types for the entire 146 river miles of the study area and the associated floodplain, at a spatial resolution sufficient to resolve important estuarine and floodplain features, wherever possible. Thus, in addition to the small scale (30 m pixel size) satellite imagery covering the study area described in this report, we also acquired high spatial resolution imagery ( $\sim 1.5 \mathrm{~m}$ pixel size) for key portions of the study area using a Compact Airborne Spectrographic Imager (CASI). Compared to the rather coarse, low spectral resolution of the satellite imagery, the CASI imagery provides the spectral resolution (19 CASI bands vs. 7 ETM+ Bands) necessary to discriminate between spectrally similar vegetation types and thus provided a greater ability to resolve habitat features important to species such as salmonids. Unfortunately, image acquisition costs and logistics (time and 
poor weather) prevented complete coverage of the study area at a $1.5 \mathrm{~m}$ spatial scale. However, in 2000/01 CASI imagery was collected for several key focal areas including the Chinook watershed, the area around the Astoria Airport mitigation site, Russian Island, Tenasillahe Island, Sauvie Island, Scappose Bay lowlands, Lord and Walker Islands and much of the shoreline.

Although the Landsat 7 ETM+ imagery is too coarse and lacks the spectral resolution to resolve many estuarine features important to natural resource managers, it does provide a broad-brush description of the estuarine cover classes and will establish the first level of a hierarchical classification scheme and a landscape perspective for the high spatial resolution imagery. This report presents the classification methodology and initial results from the satellite image classification. Results from the classification and analysis of the high spatial resolution CASI imagery are presented elsewhere as part of Phase III of this project (Garono et al., 2003). Although the two sets of imagery vary in spatial scale, they will be referenced to real world coordinates and thus form a spatially linked hierarchical habitat cover data set that will be used to support conservation and restoration efforts of the Estuary Partnership.

\section{Methods}

We acquired two Landsat 7 ETM+ scenes for this project: the western scene (47/28) was acquired at 18:54:49 UTC on 24 MAR 2000 and the eastern scene (46/28) at 18:47:36 UTC on 07 JUL 2000 (Fig. 2). Both satellite scenes were acquired on outgoing tides at relatively low tidal heights, $0.6 \mathrm{ft}$ (Mar) and $0.3 \mathrm{ft}$ (Jul: calculated with Tides \& Currents Pro, Ver. 3.0i, Nobletech Corp. for the Tongue Pt. Station in Astoria, OR). The Landsat 7 ETM+ imagery includes both multispectral and higher spatial resolution panchromatic components. 


\section{Geocorrection and Elevation Mask}

We used a nearest neighbor approach (to avoid spectral mixing) to geocorrect and orthorectify each Landsat 7 ETM+ image using 1:24,000 digital elevation data (DEM). The two scenes were orthorectified using USGS DOQQs for the ground control points and USGS 10 meter DEM as the elevation model. We reprojected the images to the Estuary Partnership projection (Lambert Conformal Conic, 1st Std Parallel - 43:00:00 N, 2nd Std Parallel - 45:30:00 N, Central Meridian - 120:30:00 W, Latitude of Origin - 41:45:00 N, False Easting 400000 meters, GRS1980, NAD83, and horizontal units in meters (not international feet)). We used a mask generated from (DEM) data to remove upland areas from the classification in order to focus the classification on estuarine and tidal freshwater floodplain habitats. Areas that were not located along the river and were $>53.24 \mathrm{~m}(175 \mathrm{ft})$ in the eastern Landsat 7 ETM+ scene and > $30.48 \mathrm{~m}$ (100 ft) in the western scene were removed from the classification. The area near the mouth of the river was interactively masked to constrain the area rather than having it continue north and south along the coast where the elevation was $<100 \mathrm{ft}$. Due to the Estuary Partnership's interest in the Chinook River watershed, we also classified and considered separately a portion of the upper Chinook watershed in this study.

\section{Tidal / Diked / Upland Map}

We were interested in separating diked areas from those with unrestricted tidal flow. To do this, we used DEMs, the TM imagery, available Dike District Maps, and persons familiar with diked areas in the CRE.

Initially, we generated a set of polygons depicting tidally influenced areas by selecting areas with elevations $<15 \mathrm{ft}$ from the DEMs. We chose an elevation of $15 \mathrm{ft}$ because it coincides with the elevation at the base of Bonneville Dam, which is considered the endpoint of the extent of tidal influence. However, use of the $15 \mathrm{ft}$ elevation polygons failed to capture all areas in the Chinook area because of the large number of diked areas. To resolve this issue a workshop 
was held at Sea Resources in Chinook, WA where information on the location of dikes was collected from written reports and persons familiar with the area.

For the workshop, we used the TM imagery to prepare a series of $3^{\prime} \times 4^{\prime}$ maps. We found that large herbaceous tracts were potentially a good indicator of diked areas. Therefore, we plotted large areas dominated by herbaceous vegetation on base maps. These maps were then compared to Dike District Maps, digital orthoquads (DOQ) and other photography, evaluated by knowledgeable personnel at a Sea Resources workshop. The maps were annotated with known dike locations. To make the final Tidal / Diked / Upland Map, diked areas were overlain on the previously mapped tidal area. The upland map was then combined with the previously mapped landcover to make tidal, diked and upland subclasses for the herbaceous, shrub scrub, deciduous forest, coniferous forest and mixed forest categories. The area outside of the Tidal/ Diked/ Non-Tidal Wetland areas were considered to be uplands.

\section{Training Data}

To classify the imagery, we used "training" information collected from a variety of sources including: other imagery and photography, i.e., an IRS panchromatic scene, USGS digital orthoquads (DOQ), color infrared photographs, and aerial videography; field measurements and observations; and aerial reconnaissance.

Training sites were identified from the videotapes, photographs, and DOQs. We collected airborne videography for this project from 19-23 Aug 2001 using a DeHavilland Beaver (operated by Ecotrust) flown at an altitude of 1,140 m AGL at approximately 176-183 km hr-1. The video imagery was collected during the CASI flights and covered only a portion of the study area. Handheld cameras captured images from some of the remaining areas. A GIS coverage of approximately 400-500 training sites was constructed from representative homogenous areas of each of the initial cover classes (described below). The spatial extent and cover class information from training sites was transferred to 
the GIS coverage (using the satellite imagery as a base map) using heads up digitization (Fig. 3). Before the coverage was used in image classification, we created a $3 \times 3$ pixel sub-sample from each of the training site polygons. This was done to standardize the area of comparison and to eliminate pixels that were near the training site edges (edge pixels may combine reflectance spectra from at least two types of cover classes). Some of the sites were too small or not wide enough for a $3 \times 3$ pixel area and were dropped; however, many of these sites were used to classify the CASI imagery. Sites were then divided into two groups, one for classification and another group for classification accuracy assessment. We used 244 sites as classification training sites. Remaining sites (not used in the classification) were combined with 195 observations derived from photos taken during a series of helicopter flights made in January and July 2002 , and with a number of digital photographs taken on the ground of specific cover classes. Photograph locations were recorded with GPS or in some cases referenced to benchmarks visible in the imagery. All sites not used in the classification were used to perform a classification accuracy assessment.

\section{Classification}

Initially we identified 15 cover classes on the basis of spectral data alone. Later, spectral classes were divided into diked, tidal and non-tidal categories using DEM and dike locations.

Training sites were selected to represent the following habitat cover classes: (1) Herbaceous Wetland, (2) Herbaceous Upland, (3) Scrub-Shrub Wetland, (4) Scrub-Shrub Upland, (5) Mud, (6) Sand, (7) Deciduous Forest Wetland, (8) Deciduous Forest Upland, (9) Coniferous Forest Wetland, (10) Coniferous Forest Upland, (11) Mixed Forest Wetland, (12) Water, (13) Mixed Forest Upland, (14) Urban, and (15) Other (e.g., log rafts). These cover classes were developed during a series of Estuary Partnership meetings and workshops. Cover classes were meant to focus specifically on estuarine and tidal freshwater habitats. Urban areas were identified from the unclassified imagery, DOQs and 
other aerial photography. The 'Sand' cover class was defined as having $70 \%$ of the area as exposed sand: exposed sand was identified in aerial photographs and during a series of site visits. The 'Mud' cover class was defined as having $70 \%$ of the area as exposed mud: exposed mud was identified in aerial photographs and during a series of site visits. Forested cover classes were identified in unclassified TM imagery and on DOQs. We defined forested classes as having compositions > $60 \%$ of conifers or broadleaved vegetation for each respective cover class.

Mixed forest classes had proportions of conifers to deciduous ranging from 40/60 to $50 / 50$. Herbaceous classes had $>70 \%$ herbaceous cover. Shrub-Scrub classes had $>70 \%$ shrub (woody vegetation $<8 \mathrm{ft}$ high) cover.

We used ERDAS ImagineTM to perform an unsupervised ISODATA classification on the two Landsat 7 ETM + scenes, separately. In addition, the Chinook (WA) area was processed separately from other areas in the western scene because of haze over that region in the image. The initial unsupervised classification, along with a Maximum Likelihood classifier resulted in 100 spectral categories for each scene. The 244 training sites were then used to assign cover classes during the supervised classification. Problem areas that showed mixing of the desired landcover classes were then extracted and reclassified in an interactive fashion until acceptable classification accuracy levels were reached.

Once areas were assigned to one of the 15 Major (spectral) cover classes, the diked areas mask (described above) was applied and the following cover classes identified: (1) Mud; (2) Sand; (3) Herbaceous Wetland - Tidal; (4) Herbaceous Wetland - Diked; (5) Herbaceous Wetland - Non-tidal; (6) Scrub Shrub - Wetland - Tidal; (7) Scrub Shrub - Wetland - Diked; (8) Scrub Shrub Wetland - Non-tidal; (9) Coniferous Forest Wetland - Tidal; (10) Coniferous Forest Wetland - Diked; (11) Coniferous Forest Wetland - Non-tidal; (12) Mixed Forest Wetland - Tidal; (13) Mixed Forest Wetland - Diked; (14) Mixed Forest Wetland - Non-tidal; (15) Deciduous Forest Wetland - Tidal; (16) Deciduous Forest Wetland - Diked; (17) Deciduous Forest Wetland - Non-tidal; (18) 
Herbaceous Upland; (19) Scrub Shrub - Upland; (20) Coniferous Forest Upland; (21) Mixed Forest Upland; (22) Deciduous Forest Upland; (23) Water; (24) Urban; (25) Clouds, shadows; and, (26) Other (log rafts, etc.). Therefore, the final habitat cover classes were defined on the basis of spectral and elevation data, and the presence of dikes.

\section{Results}

We classified estuarine and tidal freshwater habitat cover types along $\sim 146$ mi of the lower Columbia River, encompassing an area of 193,000 ha (Fig. 4a-d). While we did classify some of the upland areas in the Chinook watershed (Figure 4a), most of the upland areas along the lower Columbia River were excluded by a DEM (elevation) mask. As we expected, the largest cover class was the deep-water class, which covered $30.9 \%$ of the area (Table 1 ). We found that much of the study area was vegetated: herbaceous and woody (shrub-scrub and forested) vegetation cover classes accounted for $29.9 \%$ and $23.4 \%$ of the classified area, respectively. Vegetated wetland cover classes (herbaceous, shrub-scrub and forested) accounted for $32.0 \%$ of the study area and non-vegetated cover classes (mud and sand flats) subject to tidal inundation accounted for an additional $4.4 \%$ of the study area. We found that almost $20 \%$ of the study area was diked; this is about twice the area of tidally influenced wetlands. The urban cover class accounted for $10.8 \%$ of the area classified. Vegetated upland cover classes accounted for $21.3 \%$ of the area classified.

\section{Spatial Accuracy}

We orthorectified the two Landsat 7 ETM+ scenes using USGS DOQQs for the ground control points and USGS 10 meter DEM as the elevation model. Resulting Root Mean Square Error (RMSE), in pixels, for the 46/28 scene 
Table 1. Areas (ha) and proportion of total area for each of the cover classes derived from the classification of two YR2000 Landsat 7 ETM+ scenes from the Lower Columbia River Estuary. Also shown are the habitat cover areas for the Upper Chinook Watershed.

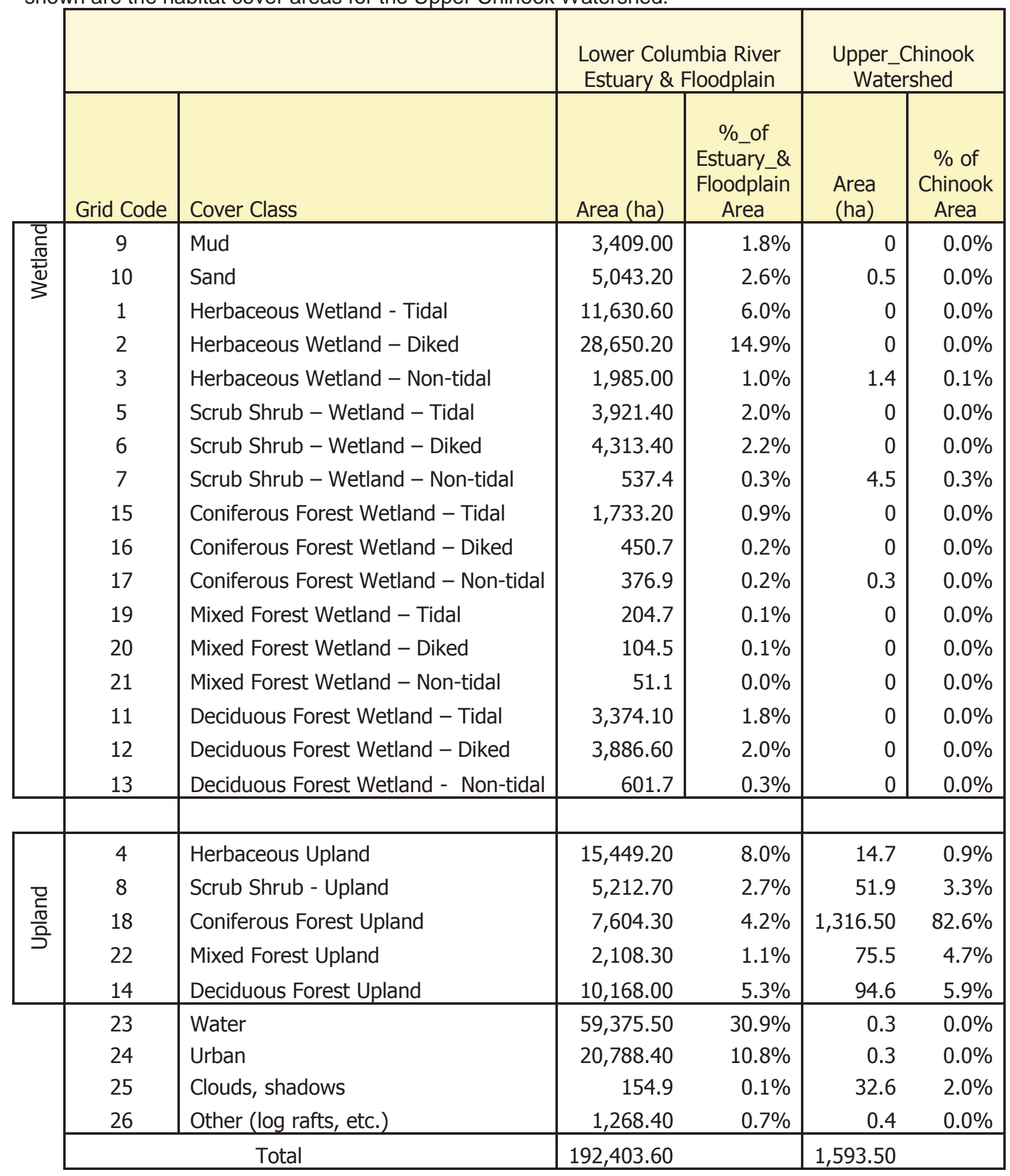


Table 2. Classification accuracy assessment of two YR2000 Landsat 7 ETM+ scenes from the Lower Columbia River Estuary. Shown are the number of accuracy assessment sites and percentage of the sites correctly classified. See text for details.

\begin{tabular}{|c|c|c|c|c|c|c|}
\hline Grid Code & Cover Class & $\begin{array}{l}\text { Ref } \\
\text { Total }\end{array}$ & $\begin{array}{c}\text { Classified } \\
\text { Total }\end{array}$ & $\begin{array}{c}\text { Number } \\
\text { Correct }\end{array}$ & $\begin{array}{c}\text { Producers } \\
\text { Accuracy }\end{array}$ & $\begin{array}{c}\text { Users } \\
\text { Accuracy }\end{array}$ \\
\hline 0 & Background & 0 & 1 & 0 & --- & --- \\
\hline 1 & Herbaceous Wetland - Tidal & 30 & 35 & 29 & $96.7 \%$ & $82.9 \%$ \\
\hline 2 & Herbaceous Wetland - Diked & 26 & 29 & 26 & $100.0 \%$ & $89.7 \%$ \\
\hline 3 & Herbaceous Wetland - Non-tidal & 7 & 8 & 7 & $100.0 \%$ & $87.5 \%$ \\
\hline 4 & Herbaceous Upland & 7 & 6 & 5 & $71.4 \%$ & $83.3 \%$ \\
\hline 5 & Scrub Shrub Wetland - Tidal & 17 & 15 & 14 & $82.4 \%$ & $93.3 \%$ \\
\hline 6 & Scrub Shrub Wetland - Diked & 6 & 5 & 4 & $66.7 \%$ & $80.0 \%$ \\
\hline 7 & Scrub Shrub Wetland - Non-tidal & 1 & 1 & 1 & $100.0 \%$ & $100.0 \%$ \\
\hline 8 & Scrub Shrub Upland & 10 & 8 & 8 & $80.0 \%$ & $100.0 \%$ \\
\hline 9 & Mud & 3 & 3 & 3 & $100.0 \%$ & $100.0 \%$ \\
\hline 10 & Sand & 7 & 9 & 7 & $100.0 \%$ & $77.8 \%$ \\
\hline 11 & Deciduous Forest Wetland - Tidal & 9 & 10 & 8 & $88.9 \%$ & $80.0 \%$ \\
\hline 12 & Deciduous Forest Wetland - Diked & 6 & 5 & 5 & $83.3 \%$ & $100.0 \%$ \\
\hline 13 & Deciduous Forest Wetland - Non-tidal & 1 & 1 & 1 & $100.0 \%$ & $100.0 \%$ \\
\hline 14 & Deciduous Forest Upland & 7 & 6 & 5 & $71.4 \%$ & $83.3 \%$ \\
\hline 15 & Coniferous Forest Wetland - Tidal & 7 & 7 & 6 & $85.7 \%$ & $85.7 \%$ \\
\hline 16 & Coniferous Forest Wetland - Diked & 3 & 4 & 3 & $100.0 \%$ & $75.0 \%$ \\
\hline 17 & Coniferous Forest Wetland - Non-tidal & 0 & 0 & 0 & --- & --- \\
\hline 18 & Coniferous Forest Upland & 7 & 10 & 6 & $85.7 \%$ & $60.0 \%$ \\
\hline 19 & Mixed Forest Wetland - Tidal & 6 & 2 & 2 & $33.3 \%$ & $100.0 \%$ \\
\hline 20 & Mixed Forest Wetland - Diked & 0 & 0 & 0 & --- & --- \\
\hline 21 & Mixed Forest Wetland - Non-tidal & 1 & 1 & 0 & $0.0 \%$ & $0.0 \%$ \\
\hline 22 & Mixed Forest Upland & 10 & 8 & 8 & $80.0 \%$ & $100.0 \%$ \\
\hline 23 & Water & 13 & 2 & 2 & $66.7 \%$ & $100.0 \%$ \\
\hline 24 & Urban & 14 & 14 & 14 & $100.0 \%$ & $100.0 \%$ \\
\hline 25 & Clouds, shadows & 0 & 0 & 0 & --- & --- \\
\hline \multirow[t]{2}{*}{26} & Other (log rafts, etc.) & 3 & 2 & 2 & $66.7 \%$ & $100.0 \%$ \\
\hline & Totals & 191 & 191 & 166 & & \\
\hline
\end{tabular}


(eastern) was $X=0.2031$ and $Y=0.2036$ (Total $=0.3077$ ) and for the $47 / 28$ scene (western) was $X=0.3640$ and $Y=0.2659$ (Total $=0.4508$ ).

\section{Classification Accuracy}

The final classification had an overall classification accuracy of $86.9 \%$ (Table 2). Producer accuracy is seen from the classifier's point of view and is based on how many tested points were assigned to the proper landcover class during the classification accuracy assessment. Errors of commission, those errors that occur from pixels within the image being assigned to the wrong cover type, are included in Producer's Accuracy. User Accuracy addresses the likelihood that landcover on the ground is actually what the map says it is. Following image classification it is common to use a moving window filter to remove 'salt and pepper' in the classified image to improve map accuracy: we have not applied a moving window filter to this data set.

\section{Discussion}

Several previous studies have mapped habitat cover types along the lower Columbia River. Though they differed in methodology, they all relied on remotely sensed data in one way or another.

Thomas (1983) compared the geographic extent of five estuarine and two non-estuarine habitat types, mapped from a series of $18701: 40,000$ Coast and Geodetic Survey navigational charts, with results of a modern habitat mapping project. He interpreted and transferred information from historic navigational charts and modern maps to common 1:24,000 scale maps from the river mouth to the east side of Puget Island. Change in habitat cover classes along the lower Columbia River estuary were then measured with a planimeter from the 1:24,000 maps. Thomas found that, in general, there was a $24 \%$ loss of tidal wetland area of the lower estuary. Significant losses also occurred in the areal extent of 
'tidal swamps' (-77\%), 'swamps and marshes' (-65\%), and 'deep and medium depth water $(-16 \%)$ cover classes and there was an increase in the area of the 'shallow and flats' (+10\%) class. Thomas' 1983 study was extended from Puget Island to the Bonneville Dam by Graves et al. (1995) using a slightly different methodology. Graves et al. (1995) reported similar losses in wetland cover types during the period of 1880 to 1991 . Wetland marshes decreased in area by $\sim 20 \%$ and forested wetlands decreased by $\sim 10 \%$. Agricultural and urban cover classes showed the largest increases in area, $\sim 20 \%$ and $\sim 8 \%$, respectively. The Thomas and Graves et al. data sets are both available from the Columbia River Estuary Taskforce (CREST).

More recently, Allen (1999) generated GIS polygon layers from aerial photographs taken along the lower Columbia River in 1948, 1961, 1973, 1983 and 1991. He mapped 18 cover classes (7 upland, 11 wetland) within a $3 \mathrm{~km}$ corridor (whenever possible) from the mouth to the Bonneville Dam. By comparing this temporal sequence of photos, he was able to measure change. Allen found that during the period of 1948 to 1991 , there was a $25 \%$ decrease in the area of estuarine wetland cover classes, a $1 \%$ increase in the area of the riverine tidal wetland cover class and a $37 \%$ decrease in the riverine lower perennial wetland cover class over his study area.

Perhaps most relevant to Phase I of this study was a study completed in 1992 by NOAA as part of its Coastal Change Analysis Program (C-CAP). The CCAP study compared two Landsat Thematic Mapper (TM) satellite images, from 1989 and 1992, to measure change in habitat cover classes along the lower Columbia River. The 1992 imagery was classified using C-CAP protocols (Dobson et al., 1995) and candidate change pixels were identified through band differencing (a procedure different from the one used in the current stury). Candidate pixels were then reclassified to derive the 1989 landcover database. The next iteration of the NOAA C-CAP study is due to be released in the spring of 2004 (Shan Berkhalter, pers com). The C-CAP study area extends from the river mouth to Kalama, WA. 
Each of these previous studies differs in methodology, geographic extent, and definition the habitat cover classes. Before study results can be compared with Phase I of this study, classification schemes must be cross-walked and the geographic extents standardized.

We found that vegetated and non-vegetated wetland cover types currently account for $>36 \%$ of the study area. While tidal marshes do not generally dominate estuarine landscapes in the Pacific Northwest (Simenstad et al., 2000), the significant losses of wetland cover types reported in previous studies underscore the immediate need to assess and develop management plans involving remaining areas. We found that a significant portion (20\%) of the study area is currently diked suggesting that numerous restoration and management opportunities exist.

Examining trends in the number of hectares gained or lost within a particular habitat cover type is an important first step; however, it is difficult to translate this information into specific management actions because actions tend to occur parcel by parcel, i.e., management is tied to a place. Moreover, definitions of "important salmonid habitat" must take into account not only the amount of habitat, but also its quality and accessibility (by salmon): habitat quality and accessibility vary on a parcel-by-parcel basis. In other words, in addition to the condition of each parcel, we must also develop an understanding of how parcel position within the landscape affects its quality with respect to long-term salmon conservation and restoration efforts. Results from Phase I of this study represent the first step in reaching this goal. Phase I produced a spatial data set describing the landcover for the entire tidally influenced region of the Columbia River. As new information becomes available, it can be tied to the spatial data set produced in Phase I. In the future, it will be possible to track change, not only as percentages of habitat cover types, but also as change in quality of individual parcels and of the estuarine landscape as a whole. 


\section{Future Work}

This report and classification is a final product. Many of the cover classes identified in the first iteration of the TM classification (October, 2002) were revised following classification of the CASI imagery and application of the diked areas GIS mask. This study will form the basis for several studies either planned or currently underway.

\section{Indicators of "habitat health" and definitions of "salmonid}

habitat': The GIS layer produced from this study will be used by in future studies to develop metrics for Columbia River "habitat health" and for developing a better understanding of the current condition of salmonid habitat.

Wetland Conservation and Restoration: The GIS layers produced in this study will be useful in identifying existing wetland areas that can be targeted for conservation and restoration. The separation of diked and tidal wetlands in this data set should be especially useful for conservation/ restoration planning.

Landscape Change Analysis: We are currently completing a change analysis for areas where comparable earlier data sets exist. We recommend that this study be repeated in 2-5 years using comparable imagery and a similar methodology.

Landscape Analysis: Because a GIS data layer was produce from this study, future studies can examine the spatial arrangement of habitat cover classes. Landscape position and context can be considered when assessing the ecological importance of any particular parcel. 


\section{Data Availability}

All spatial data are available from the Lower Columbia River Estuary Partnership, 811 SW Naito Pkwy, Suite 120, Portland, OR 97240 (http://www.lcrep.org/).

\section{Acknowledgements}

This project was completed as partial fulfillment of contract Number 172000. We gratefully acknowledge the support of the Lower Columbia River Estuary Partnership, Sea Resources, the Columbia River Estuary Task Force, the U.S. Army Corps of Engineers, and the Bonneville Power Administration. We also thank Bruce Sutherland of the Estuary Partnership, project manager, George Dockray (our pilot), of ECOTRUST and the large group of volunteers coordinated by Jennie Boyd of the Estuary Partnership who made this project possible. We also thank Jennifer Burke, ODFW, for her comments on a draft version of this report. Finally, we would like to thank Crystal Elliot and Caren Crandel for their help in interpreting the volunteer plant community data. 


\section{Literature Cited}

Allen, T. H. 1999. Areal distribution, change and restoration potential of wetlands within the lower Columbia River riparian zone, 1948-1991. Corvallis, OR, Oregon State University.

Dobson, J. E., E. A. Bright, R. L. Ferguson, D. W. Field, L. L. Wood, K. D. Haddad, H. Iredale, J. R. Jensen, V. V. Klemas, R. J. Orth and J. P. Thomas. 1995. NOAA Coastal Change Analysis Program (C-CAP): Guidance for Regional Implementation, NOAA Technical Report NMFS 123, Department of Commerce: 139.

Garono, R. J., R. R. Robinson and C. A. Simenstad. 2003. Estuarine Landcover Along the Lower Columbia River Estuary Determined from Compact Airborne Spectrographic Imager (CASI) Imagery. Portland, OR, Lower Columbia River Estuary Partnership: 21 + Figures \& Appendicies.

Graves, J. K., J. A. Christy, P. J. Clinton and P. L. Britz. 1995. Historic habitats of the lower Columbia River. Astoria, OR, Columbia River Estuary Study Taskforce: 14.

Jerrick, N. 1999. The Lower Columbia River Estuary Program Comprehensive Conservation Management Plan: Volume 1. Portland, OR, The Lower Columbia River Estuary Program: 222.

NOAA. 1997. Columbia River Estuary Land Cover Change Project. Charleston, SC, NOAA Coastal Services Center.

Simenstad, C. A., G. W. Hood, R. M. Thom, D. A. Levy and D. L. Bottom. 2000. Landscape Structure and Scale Constraints on Restoring Estuarine Wetlands for Pacific Coast Juvenile Fishes. Concepts and Controversies in Tidal Marsh Ecology. M. P. Weinstein and D. A. Kreeger. Boston, MA, Kluwer Academic Publishers: 597-630.

Thomas, D. W. 1980. Study of the intertidal vegetation of the Columbia River Estuary. Astoria, OR, Columbia river Estuary Data Development Program. 
Thomas, D. W. 1983. Changes in Columbia River Estuary Habitat Types over the Past Century. Astoria, OR, Columbia River Estuary Data Development Program, Columbia River Estuary Task Force: 50 pp. 


\section{Figures}

Figure 1. The study area. Shown is the DEM-masked classified Landsat 7 ETM+ imagery on an unclassified image mosaic. The two Landsat 7 ETM+ images were acquired on 24 Mar and 7 Jul 2000 for this project.

Figure 2. Geographic extent of the two Landsat 7 ETM+ images classified for this project (black boxes). Also shown are IRS satellite images either considered or acquired for this project.

Figure 3. Example of image classification training and accuracy assessment sites (yellow) captured from airborne digital videography and transferred to an unclassified mosaic of Landsat 7 ETM+ images.

Figure 4a-d. Estuarine and tidal freshwater cover classes (major spectral classes) of the CRE derived from classification of DEM-masked Landsat 7 ETM+ imagery (Mud = gray, Sand=gold, Wetlands =green, Uplands =light blue, Water= dark blue, and Urban Areas $=$ red). Figure 4a shows the Chinook Watershed upland extension area (yellow box) that was classified as part of this project: this area is not part of the estuary/ riparian floodplain study area. These cover classes were further divided by using DEM and dike locations (see text for details). 


\section{Lower Columbia River}

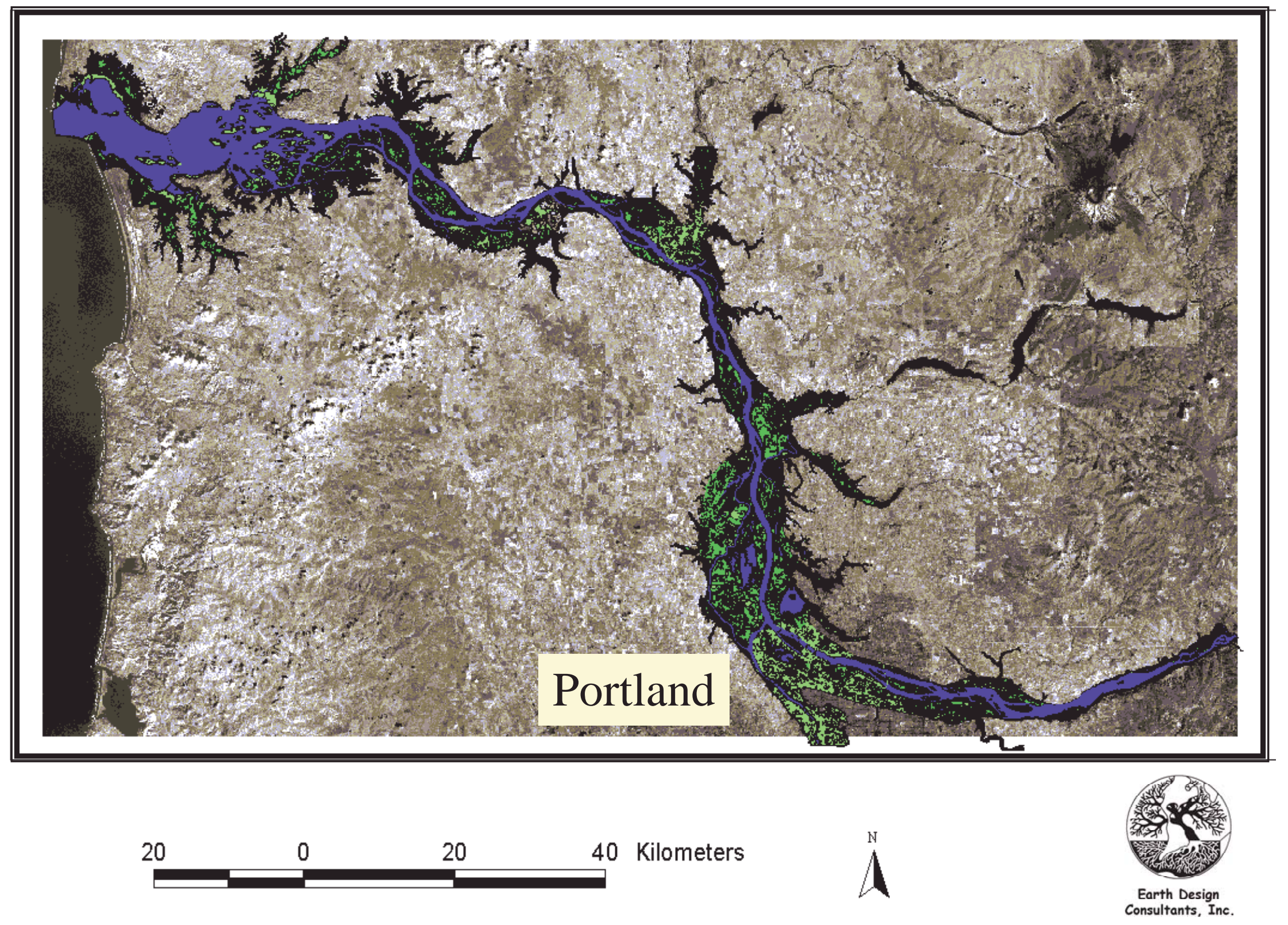


Figure 2

\section{Two Landsat 7 ETM Images were acquired}

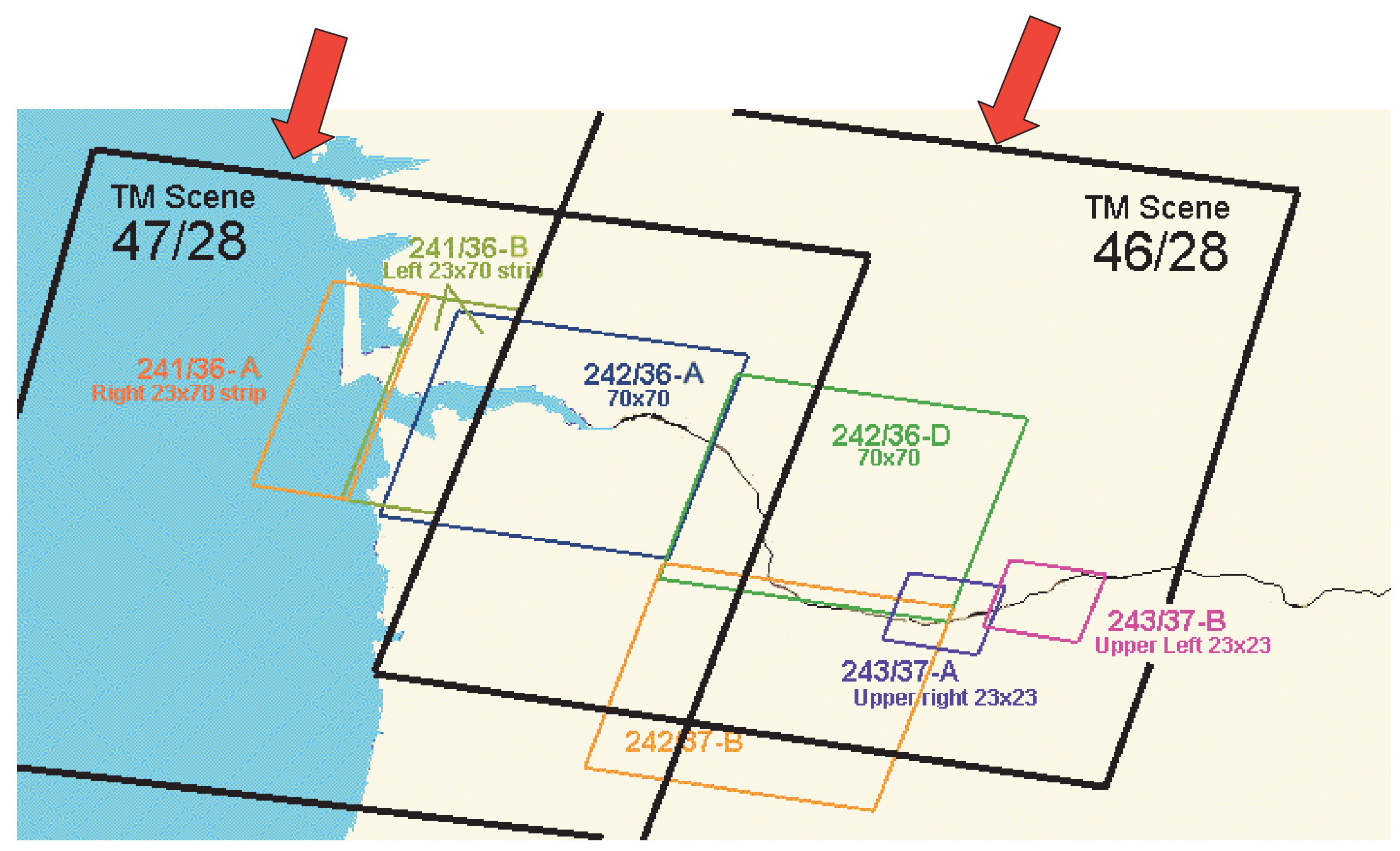


Figure 3

\section{Lower Columbia River Estuary}

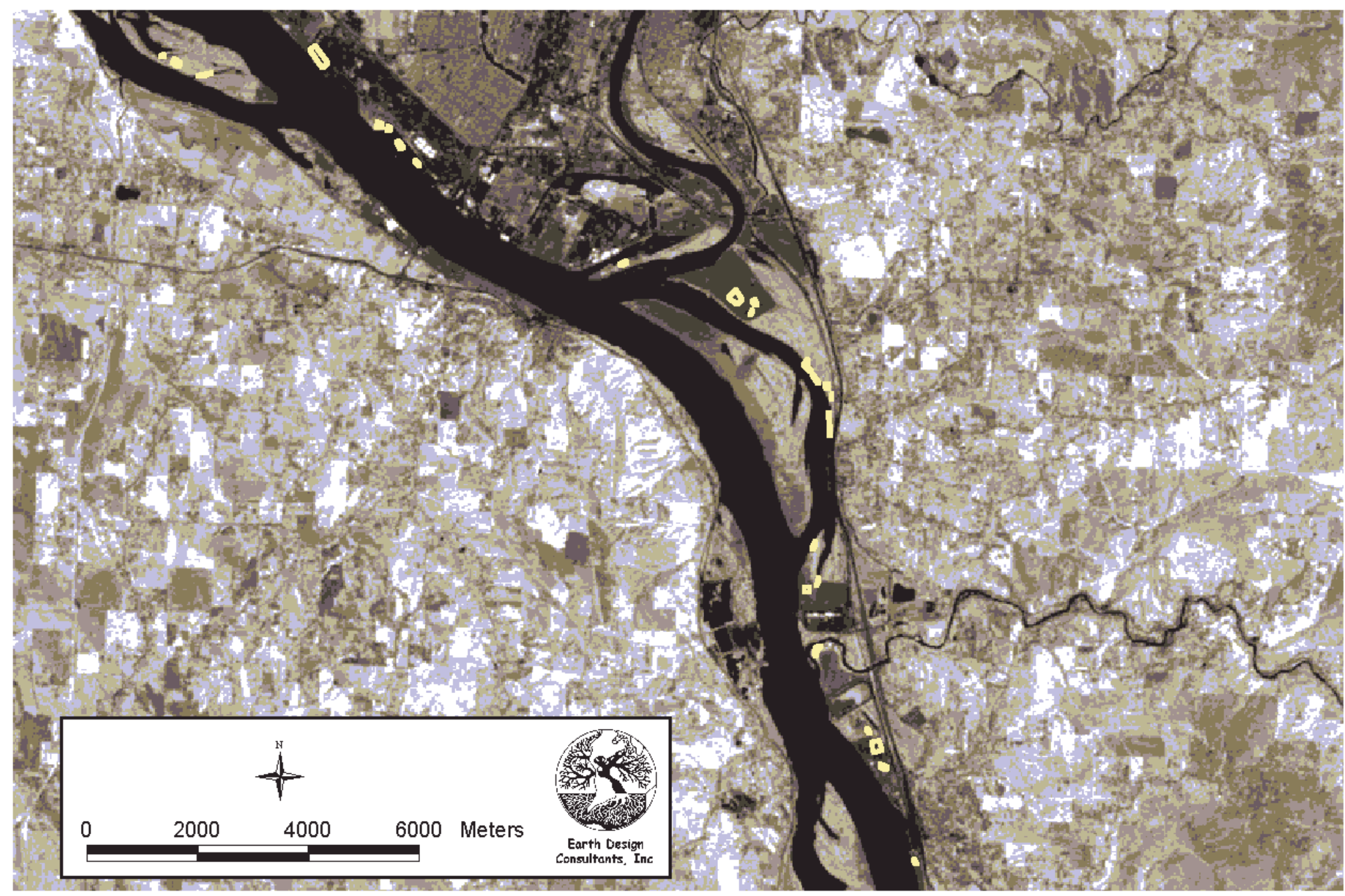


Figure 4a

\section{Lower Columbia River Estuary}

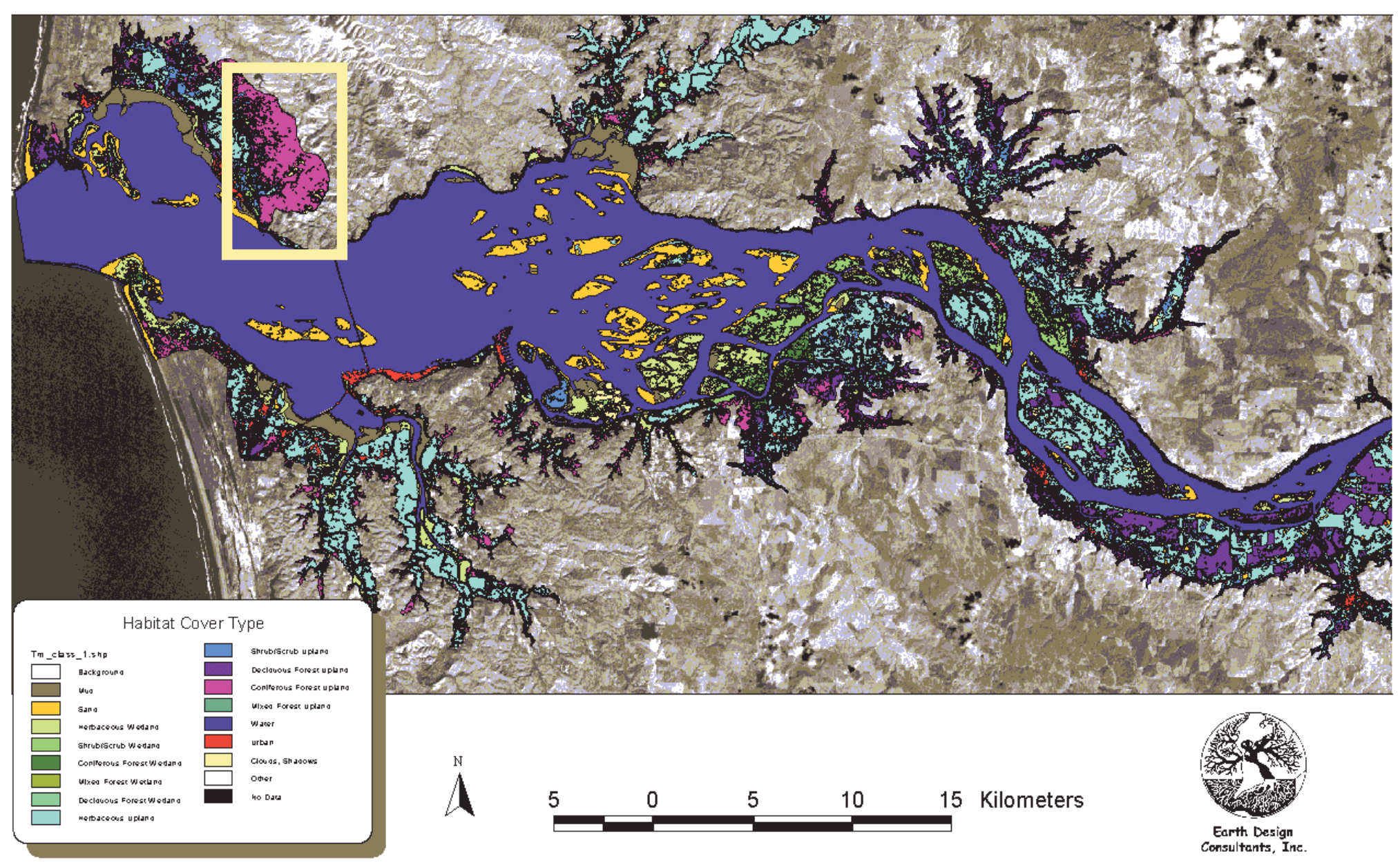




\section{Lower Columbia River Estuary}

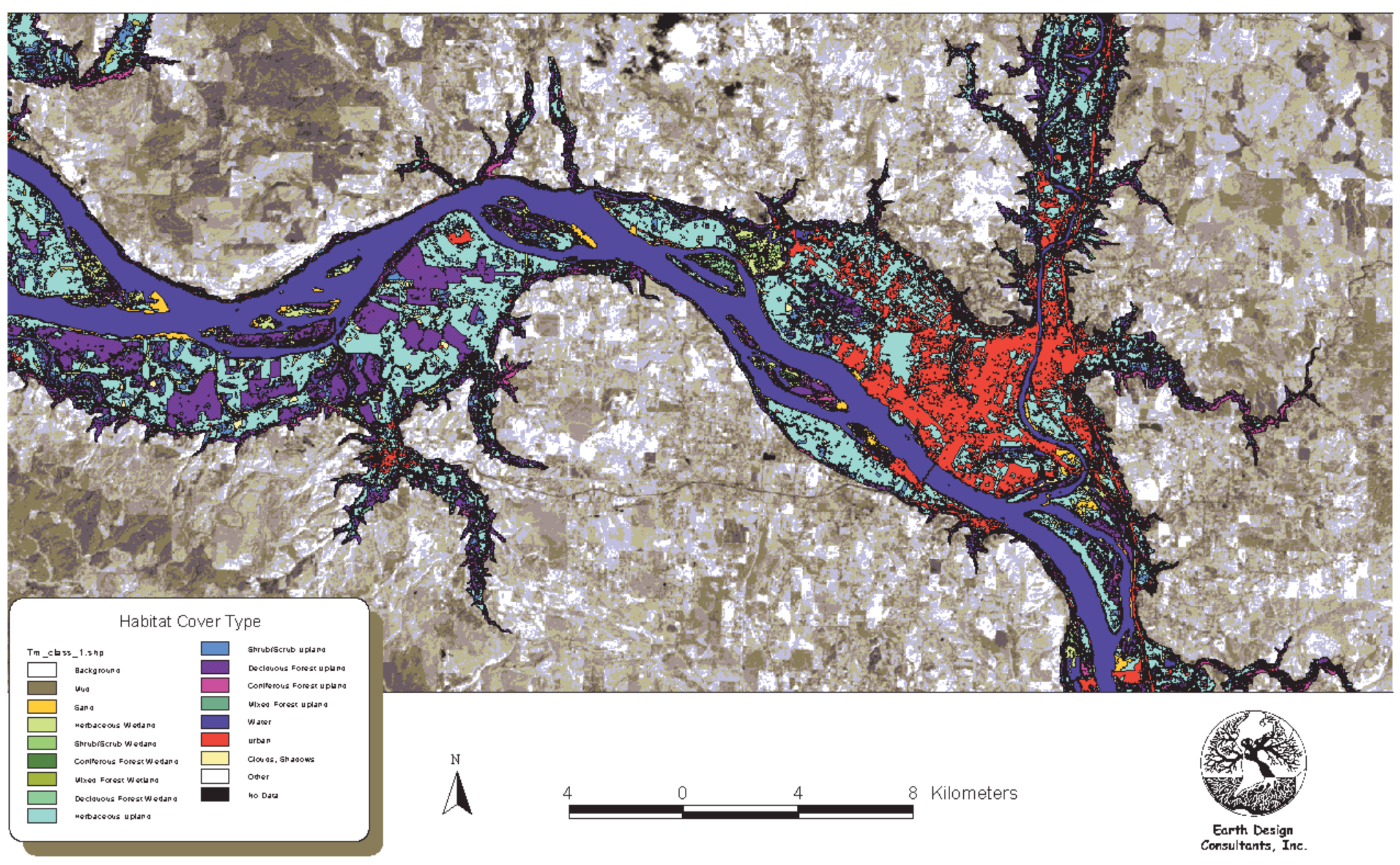


Figure 4c

\section{Lower Columbia River Estuary}

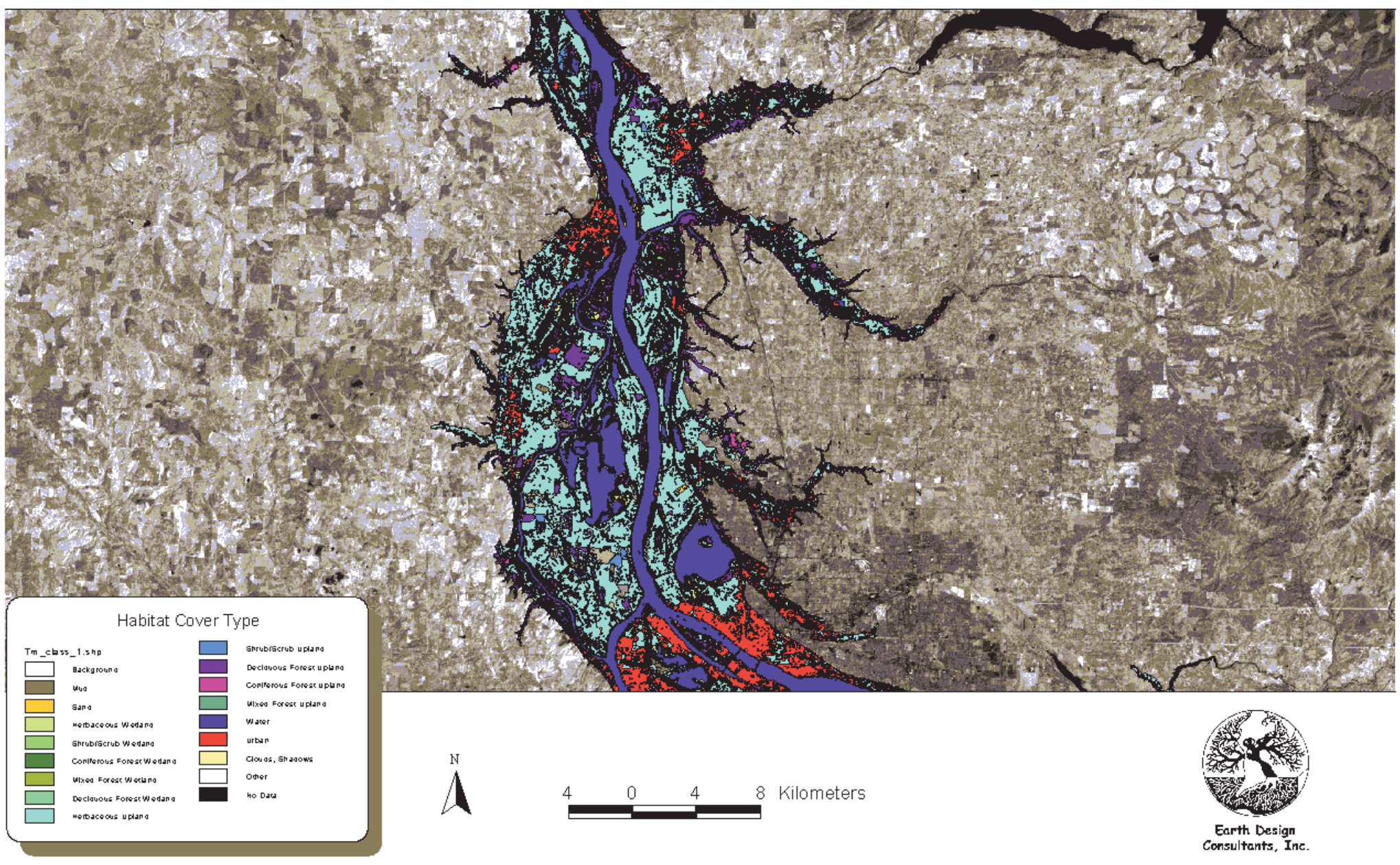


Figure 4d

\section{Lower Columbia River Estuary}

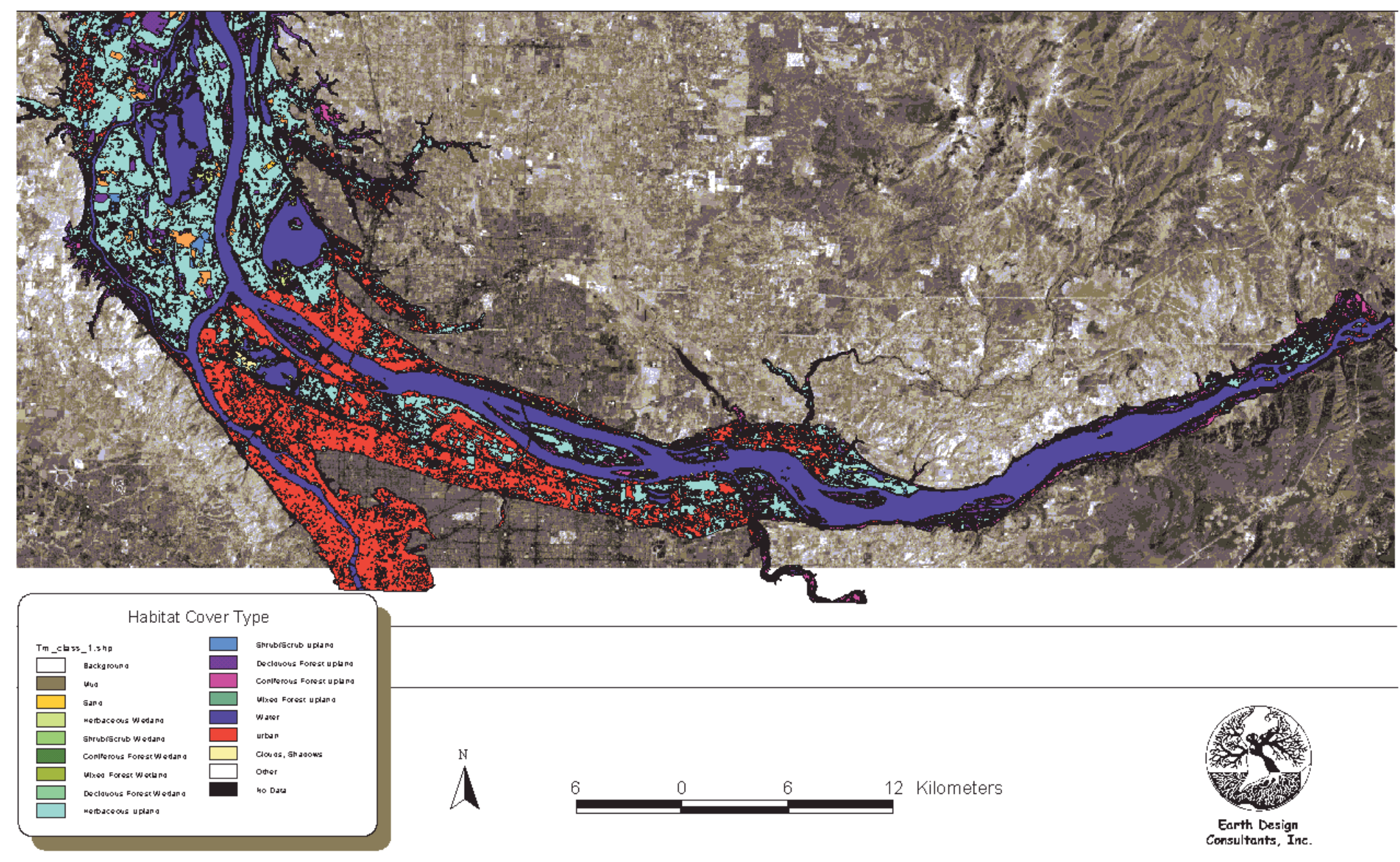

